\title{
Experiência e percepção da Natureza na Infância
}

\section{Experience and Perception of Nature in Childhood}

\section{Jéssica Aparecida Porfirio da Silva ' 1 , Jeani Delgado Paschoal Moura}

\author{
'Universidade Estadual de Londrina, Londrina, PR, Brasil
}

"Universidade Estadual de Londrina, Londrina, PR, Brasil

\section{RESUMO}

A sociedade moderna tem apresentado um movimento de afastamento em relação a natureza, levando a perda da conexão entre homem-natureza. Desde a sua primeira infância, a criança interage com o mundo em resposta a estímulos externos revelando, por meio da sua corporeidade, a singularidade com que interpreta o mundo ao seu redor. A natureza propicia um ambiente favorável para a criança desenvolver diversas habilidades, ampliando as suas memórias e sensações. O objetivo da pesquisa foi compreender a relação da criança com a natureza por meio de suas percepções e experiências numa fase decisiva do seu desenvolvimento corporal, pessoal e da construção de valores. Fundamentada pela Fenomenologia da experiência e da imaginação, esta pesquisa qualitativa apresenta experimentações de interação da criança na natureza. Como resultado, observou-se que as crianças necessitam manter um contato com a natureza fora delas, criando laços com o seu eu/natural e enxergando-se como parte da natureza. Conclui-se que a valorização das experiências da criança em relação ao mundo em si e com a natureza, é um caminho possível para o seu desenvolvimento humano e altruísta.

Palavras-chave: Criança; Corporeidade; Homem-natureza

\section{ABSTRACT}

Modern society has shown a movement of deviation from nature, leading to a connection loss between man and nature. Since their early childhood, children interact with the world in response to external encouragement, revealing through their corporeality, the uniqueness with which they interpret the world around them. Nature provides a favorable environment for children to develop various skills, expanding their memories and sensations. The purpose of this research was to understand the child's relationship with nature through their perceptions and experiences at a decisive stage in their corporal and personal development, and the construction of values. Based on the phenomenology of experience and imagination, this qualitative research presents experiments on the interaction of children in the nature. As an outcome, it was observed that children need to maintain contact with nature outside them, creating amends with their natural selves and seeing themselves as part of nature. It is concluded that the valorization of the child's experiences in relation to the world itself and with nature is a possible path for their human and altruistic development. 
Keywords: Child; Corporeality; Man-nature

\section{INTRODUÇÃO}

Esta pesquisa é parte integrante de uma pesquisa mais ampla (SILVA, 2019) que emergiu da necessidade de investigar a criança, em sua corporeidade, por meio das relações com o mundo circundante, especialmente, no contato com a natureza presente no ambiente urbano. Entendemos por corporeidade a maneira pela qual o cérebro reconhece e utiliza o corpo como instrumento relacional com o mundo (OLIVIER, 1995). Para Merleau-Ponty (2006) não há oposição entre o humano e o natural, pois o corpo permite existir/viver, ver e conhecer o mundo. Dardel (2011) explorou a ligação do homem com a Terra ou as suas geograficidades e Tuan (2012) buscou entender o mundo humano por meio do estudo das relações pessoais com a natureza e o ambiente, seu comportamento geográfico, seus sentimentos e ideias a respeito do espaço e do lugar. O presente estudo se sustenta nessas ideias para compreender a importância do contato com a natureza durante a infância, tendo como fio condutor as premissas da Geografia Humanista de base fenomenológica. A criança que vive na cidade, em contato com o espaço construído como, ruas pavimentadas, casas, prédios e outras construções, bem pouco experiencia a natureza natural e, via de regra, não percebe a ação transformadora e dinâmica que acontece na construção das casas e prédios e/ou dos produtos primários embalados nas prateleiras, ou seja, não percebe a obra do homem movendo a vida na cidade. Talvez seja difícil para certas crianças imaginarem que o leite pasteurizado tem a sua origem em um processo de ordenha feita manualmente ou automatizada. É preciso ter olhos experientes para perceber que aquilo que nos rodeia provém da natureza.

A criança, em sua corporeidade, vive e experiencia o ambiente urbano, porém devido a presença de uma natureza transformada, não estabelece elos, embora seja parte desta. Em razão disso, uma visão antropocêntrica é construída ao longo da vida, sendo interiorizada pelo pensamento moderno, em que o homem adota uma posição superior às demais espécies, vendo a natureza apenas como um recurso a ser explorado. 
Mas, como aprender a respeitar a natureza se, desde a infância, o homem se mantém distante dela e não convive em sintonia com seus elementos? Esse desgarramento da natureza pode acarretar o descompromisso com a sua preservação. Por outro lado, a criança possui uma curiosidade natural pelo mundo em que vive, visto que desde cedo, na primeira infância, percorre pelos espaços, investigando-os minuciosamente, como um "pequeno geógrafo". Para que possa ser formada uma consciência ambiental permanente, em que valores e o respeito com o ambiente sejam construídos, tais laços entre criança/natureza devem ser incentivados na infância, pois essa fase da vida é decisiva para a construção de valores.

A pesquisa empírica foi possível por meio de encontros diários com crianças do $3^{\circ}$ ano do Ensino Fundamental I, no ano de 2018, em uma escola municipal, em Londrina, Paraná. A estrutura física dessa escola é de construção antiga em madeira de peroba, onde acontecem variadas brincadeiras, cujas interações sociais muitas crianças custariam a vivenciar, não fosse este lugar-escola. O pátio é composto por algumas árvores de porte grande, com raízes expostas que desnivelam o solo, ofertando sombra e beleza ao lugar. É neste cenário simples, dotado de alguns elementos da natureza, que as crianças passam a maior parte de seus dias, estas caem, se levantam, caem novamente e, vez ou outra, aparecem com os joelhos ralados na sala dos professores.

Apesar de iniciativas para colocar a criança em contato com a natureza no ambiente escolar, ainda prevalece em sala de aula a abordagem de conteúdos pedagógicos que visam a construção conceitual, pois nem sempre é possível proporcionar às crianças um conhecimento pautado em experiências empíricas mediadas pelo contato direto com o mundo natural, vivenciado por meio da relação com os componentes bióticos (animais e plantas) e abióticos (sol, chuva, ar, terra) que compõem os espaços dardelianos (telúricos, aquáticos e aéreos), pouco apreciados pelos que vivem nos espaços construídos, prevalecentes nas cidades. O ambiente de estudo de referência da criança é limitado à carteira escolar e às quatro paredes, portanto, o emparedamento da infância (TIRIBA, 2018) é perceptível no tempo-espaço escolar e o conhecimento produzido, muitas vezes, é racionalizado e objetivado, sem 
passar pelo crivo da experiência. Na proposta curricular dos conteúdos de $3^{\circ}$ ano aparece o eixo: Transformando a Natureza - as relações da sociedade com a natureza, entre outros temas a serem trabalhados interdisciplinarmente. Embasando-nos na proposta curricular integrada aos objetivos da presente pesquisa, buscamos compreender a relação criança-natureza por meio da investigação e de experimentações no espaço-tempo escolar, colocando as crianças-participantes desta pesquisa como protagonistas de aprendizagens conectadas com a vida. O objetivo da pesquisa foi compreender os diferentes modos de perceber a natureza na infância, estimulada pela experiência do contato (ou não) com os elementos naturais presentes na cidade de Londrina, Paraná. O trabalho apoiou-se na pesquisa qualitativa, em que as pesquisadoras participaram das atividades do grupo investigado, contribuindo na elucidação dos problemas levantados na pesquisa a fim de compreender o fenômeno em sua essência. Para diminuir a distância entre a teoria e prática do conhecimento, pautadas em uma lógica descritiva e compreensiva, buscamos compreender a criança, em suas percepções e experiências, mediante o contato com a natureza pelo seu corpo, "[...] onde existimos, onde nosso cotidiano real está estabelecido", acrescentando ainda que a "[...] imagem, a sensação, o cheiro, e os sons de uma paisagem cercam o indivíduo desde o começo da vida" (LOUV, 2016, p.76).

A metodologia de pesquisa qualitativa integrada às experimentações pedagógicas, se desenvolveu por meio de um olhar sensível, intuitivo e, ao mesmo tempo, investigativo, partindo da observação da interação da criança com a natureza e como esta expressa as suas percepções. Como parte da construção da pesquisa observamos como as crianças se relacionam, brincam e percebem a natureza a partir da experiência e percepção. Nossos "pequenos geógrafos", foram estimulados a pensar, experienciar, perceber e imaginar a natureza. Para alcançar o que esta pesquisa se propôs foram realizados diversos momentos de interação com/entre as crianças na busca de informações empíricas, como desenhos de paisagens e narrativas registradas em suas memórias, além de uma aula-passeioi em uma paisagem à disposição do corpo, neste caso o Jardim Botânico, cartão postal de Londrina. O modo como as crianças se 
posicionam ao entrar em contato com um ambiente natural, pode ajudar na compreensão de como percebem e se relacionam com a natureza fora delas, principalmente, através das brincadeiras, ferramenta primordial para a sua interação com o mundo. Este artigo está organizado em duas partes: a primeira, Percepção, Experiência e Imaginação na Infância, discute a relação entre percepção, experiência e imaginação, buscando compreender a essência dessa tríade que permeia a relação da criança com a natureza; a segunda, Experimentações: Corpo-natureza, abordamos a noção de natureza presentificada nos desenhos infantis, nas narrativas sobre as brincadeiras preferidas e pela aula-passeio como proposta de reconexão com a natureza pelo contato criança/corpo/natureza.

\section{PERCEPÇÃO, EXPERIÊNCIA E IMAGINAÇÃO NA INFÂNCIA}

A criança é ser imaginante, "[...] para Merleau-Ponty $(2001 ; 2006)$ uma das grandes dificuldades em se discutir acerca da criança, deve-se ao fato de que a observamos do ponto de vista do adulto. Assim, nunca conseguiremos apreender totalmente este fenômeno tal qual ele ocorre" (TELLES, 2014, p.9). Para Lowenthal (1961), a experiência e a imaginação são fundamentais na construção das concepções geográficas, construindo a história e a memória do ser. A relação entre "percepção, experiência e imaginação" se dá pela intuição, observação pessoal, pelo imaginário e experiências de contato direto do sujeito com o meio, ao mesmo tempo em que pode ser instituída pelas diferentes linguagens abordadas no contexto do ensino intencional. O aproveitamento das relações com a natureza são variáveis, seja direta ou indiretamente e apresenta o impacto distinto na vida da criança (LOWENTHAL, 1961).

$\mathrm{Na}$ essência desse contato da criança com o mundo, principalmente com o mundo/natureza, "[...] o sujeito que percebe está diante do mundo como o cientista diante de suas experiências" (MERLEAU-PONTY, 2011, p.50). A noção de tempo e percepção espacial são diferenciadas se compararmos a visão de um infante a de um adulto. A memória dos espaços que frequentamos na infância, principalmente de lugares que foram importantes para nós, provoca uma sensação diferenciada em 
relação às dimensões espaciais reais. A percepção da criança, bem como a sua noção de mundo e a qualidade de sua imaginação respondem a estímulos e experiências vivenciadas em seu cotidiano, "vê-se que o fenômeno da infância se caracteriza atrelado às questões da cultura e da liberdade da criança, entendida como alguém que trava relações com o mundo da forma como lhe é possível", no espaço que the é possível e nas experiências e percepções que Ihe são permitidas, ou então pré-estabelecidas (TELLES, 2014, p.4).

A percepção é o nosso primeiro contato com as coisas e com os outros, é única e exclusiva de cada indivíduo. Duas pessoas não veem a mesma realidade, por outro lado "todos os seres humanos compartilham percepções comuns, um mundo comum, em virtude de possuírem órgãos similares" (TUAN, 2012, p.21). O que nos diferencia um dos outros é a qualidade de nossas experiências que indicam caminhos para a percepção e imaginação. Cada indivíduo desde a infância constrói a sua identidade por meio de suas percepções, experiências e sensibilidade, posicionando-se como ser social (MOURA, 2007). A existência e essência constituem o nosso ser através do corpo, no qual a nossa essência é condicionada aos nossos pensamentos, sentimentos e sensibilidade que se presentificam em nós. Tuan (2012) faz indagações que leva à reflexão sobre a nossa existência na Natureza e de nós mesmos enquanto natureza, bem como nossas ações no mundo.

Quais são nossas visões de meio ambiente físico, natural e humanizado? Como o percebemos, estruturamos e avaliamos? Quais foram, e quais são, os nossos ideais ambientais? Como a economia, o estilo de vida e o próprio ambiente físico afetam as atitudes e valores ambientais? Quais são os laços entre meio ambiente e visão de mundo? (TUAN, 2012, p.15).

As respostas a essas questões são imprescindíveis para a manutenção da vida, seja em relação à estesiologia, seja em relação à corporeidade, visto que ambas devem atuar em sintonia para a manutenção do bem estar. O nosso corpo, através dos sentidos, permite aprimorar a percepção de mundo, em que a cada imaginação, uma nova experiência é vivida (MOURA, 2007). A Fenomenologia convida a estudar o mundo e as 
relações sociais através da percepção, imaginação e experiência, "corriente filosófica que plantea «ir a las cosas como ellas son», propone una disolución progresiva de todo tipo de polaridades, para pasar a mirar el mundo como horizonte, en grados, como experiencia de la conciencia que es conciencia de algo" (ECHEVERRI, 2004, p. 39). Como defendem os pressupostos da Fenomenologia, "o homem não aprende somente com sua inteligência, mas com seu corpo e suas vísceras, sua sensibilidade e imaginação", o homem vivencia e percebe o mundo, utilizando-se de todo o seu ser (REZENDE, 1990, p. 49). "Portanto, não é preciso perguntar-se se nós percebemos verdadeiramente um mundo, é preciso dizer, ao contrário: o mundo é aquilo que nós percebemos" (MERLEAU-PONTY, 2011, p. 13,14).

$\mathrm{Na}$ infância sentimentos topofílicos em relação a natureza aparecem de forma intuitiva proporcionando às crianças momentos agradáveis e fraternos. A criança se sente livre e, ao mesmo tempo, acolhida pelo que o ambiente natural tem a lhe oferecer. $\mathrm{Na}$ contramão desses valores, pelas possibilidades restritas de brincadeiras ao ar livre em comparação aos espaços emparedados e emparelhados com televisão, computador, celular, tablet, entre outros instrumentos tecnológicos, parece tornar a natureza obsoleta. É importante destacar que "diferente da televisão, o contato com a natureza não rouba o tempo da criança, mas amplia" (LOUV, 2016, p.15).

As crianças deste estudo se enquadram em um nível de renda de baixo poder aquisitivo, um padrão de vida simples, com poucas condições financeiras, visto que parte das famílias mora em ocupações e, na maioria dos casos, é beneficiária de programas do governo, perfil socioeconômico justificado pela localização da escola. Por esta razão a maioria das crianças não faz parte da inclusão digital, por não dispor de aparelhos celulares, computadores, videogames, tablet, entre outros. Diante dessa realidade, a hipótese é de que crianças sem o acesso às mídias digitais vivenciam o mundo circundante de forma significativa. Diante da constatação de tal realidade e por meio da observação das experiências, diretas e indiretas, das crianças em seus mundos, buscamos compreender as suas vivências e percepções em relação à natureza, de forma espontânea e como fruto da intencionalidade pedagógica. 


\section{EXPERIMENTAÇÕES: CORPO-NATUREZA}

As atividades aconteceram em tempos e espaços diferenciados, pautados na Geografia Humanista de base fenomenológica que busca a essência do mundo, mas não "[...] aquilo que ele é em ideia, uma vez que o tenhamos reduzido a tema de discurso, é buscar aquilo que de fato ele é para nós antes de qualquer tematização" (MERLEAU-PONTY, 2011, p.13). A metodologia de pesquisa qualitativa se pautou na observação, na realização de oficinas de desenhos para que as crianças pudessem revelar as suas percepções em relação à natureza fora delas, rodas de conversas informais em que registramos as suas narrativas em um gravador de celular, além de uma aula-passeio no Jardim Botânico, oportunizando a vivência em um ambiente junto à natureza, onde emergiram múltiplas experiências infantis.

A primeira atividade que fez parte dessa pesquisa empírica aconteceu no espaço da sala de aula, em torno de uma oficina imaginativa de desenhos sobre a natureza conforme a percepção criativa do olhar infantil. A professora com seu raciocínio investigativo e pedagógico, levantou a seguinte pergunta fenomenológica, em sala de aula: "O que é isso - a natureza?" Assim, com suas páginas em branco, as crianças aceitaram o desafio de desenhar a natureza livremente, sem pré-conceitos determinados que pudessem interferir em sua atitude natural de imaginar e personificar o imaginado por meio de seus desenhos.

Em um segundo momento, propôs-se outra metodologia em torno de uma roda de conversas, com o objetivo de dar voz as crianças sobre o brincar em diferentes contextos. Durante a roda, cada uma pôde falar um pouco das suas brincadeiras preferidas, a professora utilizou um gravador no celular para captar seus relatos, no final, foi feita uma breve reflexão sobre as brincadeiras.

A terceira metodologia pautou-se em uma aula-passeio no Jardim Botânico de Londrina. O convite foi feito às crianças, em seguida foi mandado bilhete aos pais com as devidas autorizações para que pudessem ser retiradas da escola, acompanhadas pela professora regente, além de duas professoras para apoio e monitores da universidade e um professor universitário. Tomadas as primeiras providências, a equipe de trabalho 
com a participação das crianças, passou a se preparar para o dia do passeio num ambiente repleto de natureza, para que as crianças pudessem "brincar ao ar livre vivendo e sendo natureza" (TIRIBA, 2018, p. 24).

\subsection{Os Desenhos}

A primeira experimentação foi realizada em um único momento e dividida em duas sequências, na primeira, as crianças não se incluíram em seus desenhos, na segunda sequência, a criança aparece em meio a natureza representada. É interessante observar a extensão do imaginário infantil diante de uma folha em branco ao realizar um desenho livre sobre um tema tão amplo como a natureza, resultando em diferentes paisagens, com faunas e floras ilustradas com riqueza de diversidade e cor, sugerindo diversos ecossistemas. A singularidade na ilustração das crianças "salta aos olhos", as cores vivas e o céu azul de nuvens brancas, compõem a paisagem de um campo florido, no qual as borboletas voam vistosas sob a luz de um sol resplandecente (Figura 1).

A professora pergunta:

- Que é isso, a natureza?

As crianças desenham 
Figura 1 - Nuvens de algodão

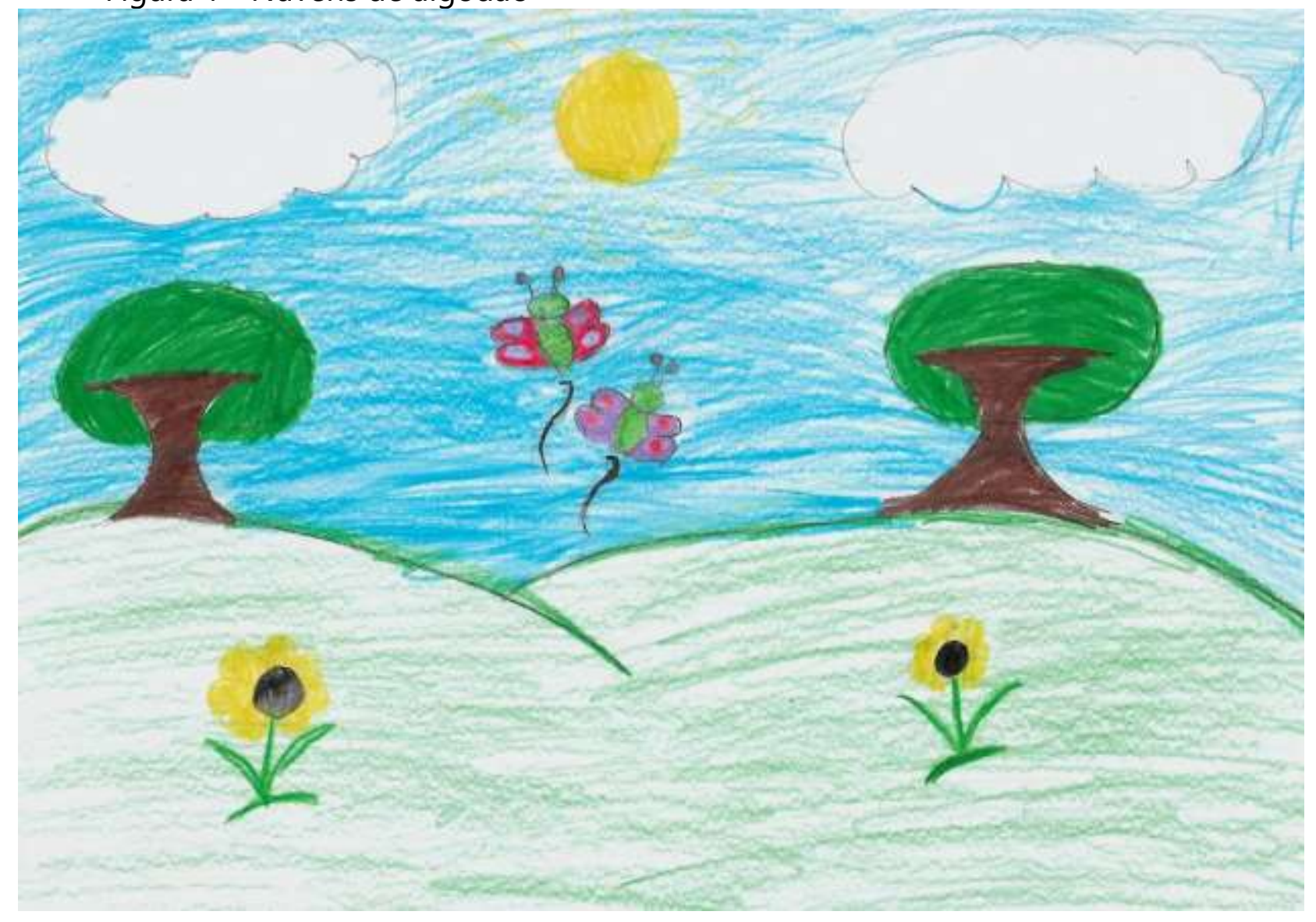

Fonte: Acervo particular dos autores (setembro de 2018).

Legenda: Desenho ilustrado por Ana Beatriz (9 anos).

$\mathrm{Na}$ figura 2 destaca-se a riqueza de detalhes que a criança traz para o desenho, o sol multicolorido, as árvores com frutos como a maça e a banana, e os animais dispostos em todo o ambiente, em uma natureza livre e exótica, com girafa, coelho, formigas a caminho do seu formigueiro, um animal aquático não identificado, uma cobra perigosa solta no meio da bicharada, um macaquinho em cima da árvore, provavelmente pronto para atacar um cacho de banana.

A professora pergunta:

- Que é isso, a natureza?

As crianças desenham

Figura 2 - Natureza criativa 


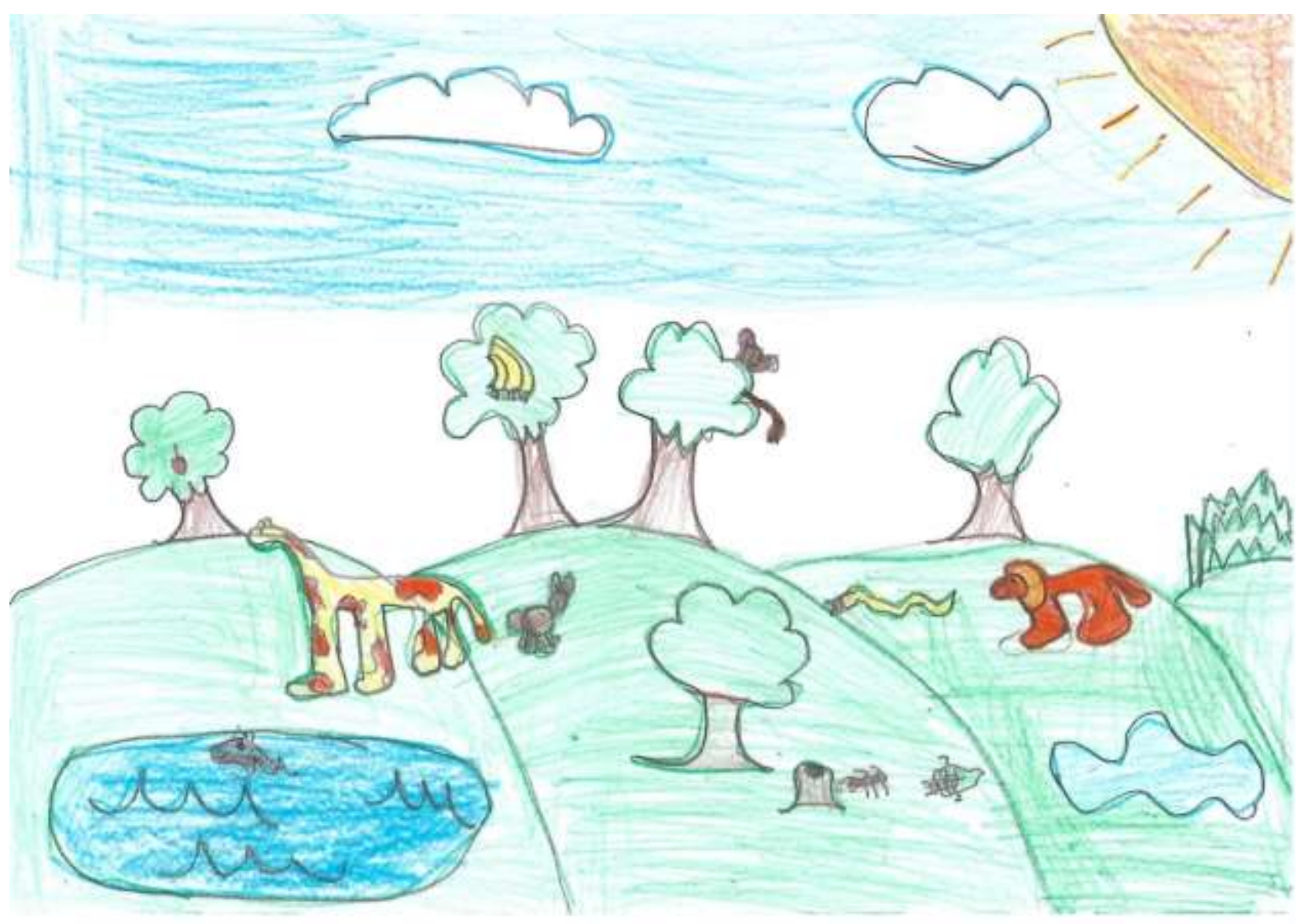

Fonte: Acervo particular dos autores (setembro de 2018).

Legenda: Desenho ilustrado por Gustavo (9 anos).

Observa-se nessas figuras a riqueza de fatores naturais que aparecem nos desenhos, uma natureza representada, principalmente, por árvores, presentes em todas as ilustrações, ademais observamos flores, animais no chão e nas árvores, lagos com peixes, sol e nuvens, frutas como banana, maça e uva, borboletas e pássaros. A criança retrata uma natureza livre de prédios, asfalto, carros, e outros elementos que configuram a cidade, com destaque para o verde das árvores, as cores das flores, o azul do céu e dos rios que tomam conta do imaginário infantil.

Na próxima figura (3), observamos a interação estreita entre indivíduo e natureza, criações diferentes que levam a reflexões acerca das percepções da criança. A diversidade de animais, pássaros, borboletas, peixes e tartarugas, sugere uma natureza preservada e em equilíbrio, na qual o ser humano apresenta-se como parte integrante e análoga, não exibindo superioridade. A natureza em harmonia, onde há um homem pescando um enorme peixe, uma rede simples entre as árvores, a criança se preparando 
para se divertir no balanço, as flores coloridas enfeitando e trazendo vida ao ambiente, além de pássaros sobrevoando a paisagem e borboletas desfilando com a sua beleza.

A professora pergunta:

- Que é isso, a natureza?

As crianças desenham

Figura 3 - Flores Coloridas
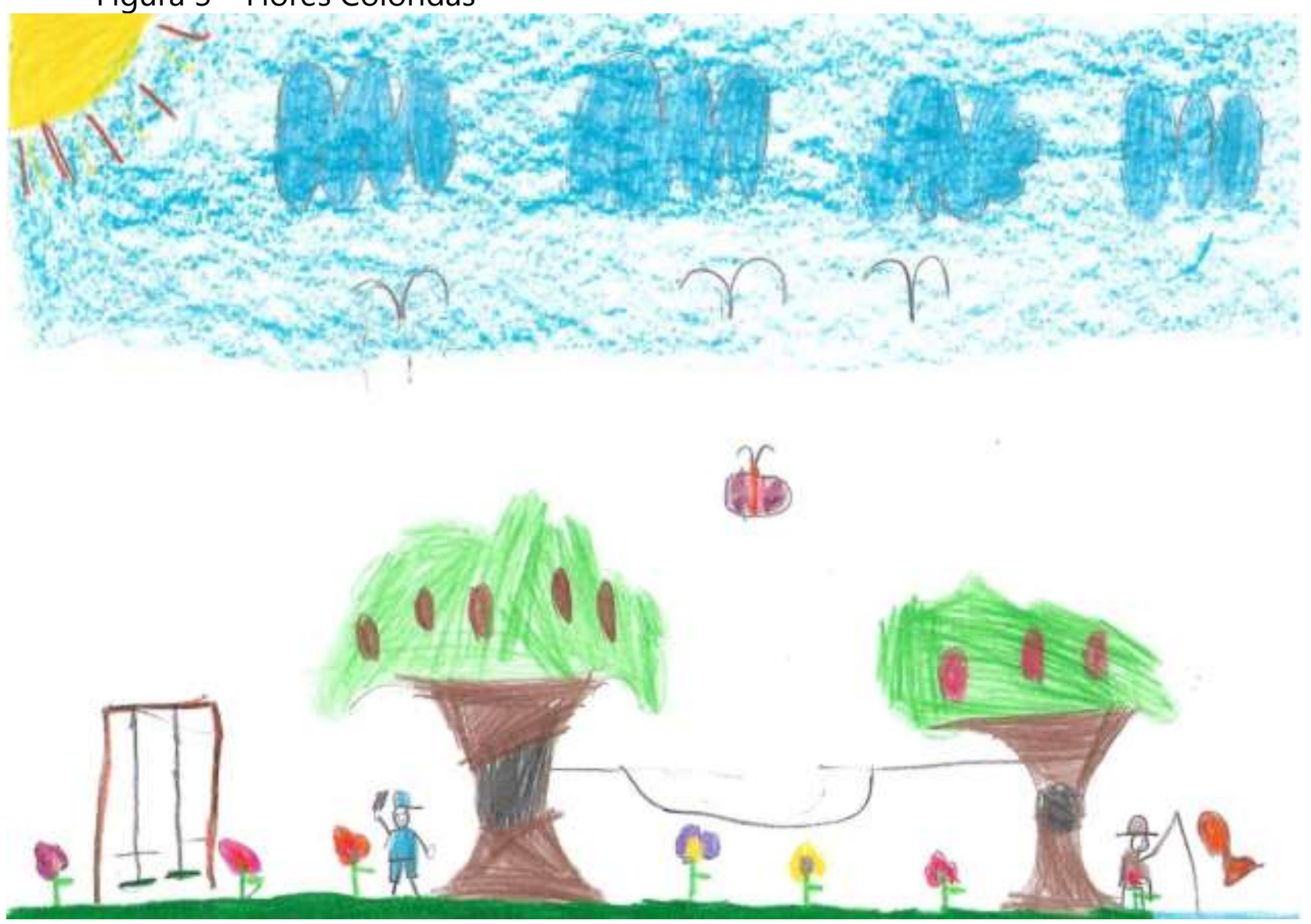

Fonte: Acervo particular dos autores (setembro de 2018).

Legenda: Desenho ilustrado por Pietro (9 anos).

Em algumas ilustrações a criança documenta seu distanciamento da natureza, apresentando-se como observadora, a exemplo da figura 4, em que a menina observa os peixes sobre uma rocha, as aves do céu e as flores do campo. Ao desenhar os peixes no chão a criança ignora a necessidade de água para esses animais. Ao posicionar-se distante da natureza a criança demonstra distanciamentos, e talvez ausências da natureza em sua vida.

\section{A professora pergunta:}


- Que é isso, a natureza?

As crianças desenham

Figura 4 - Peixes no chão
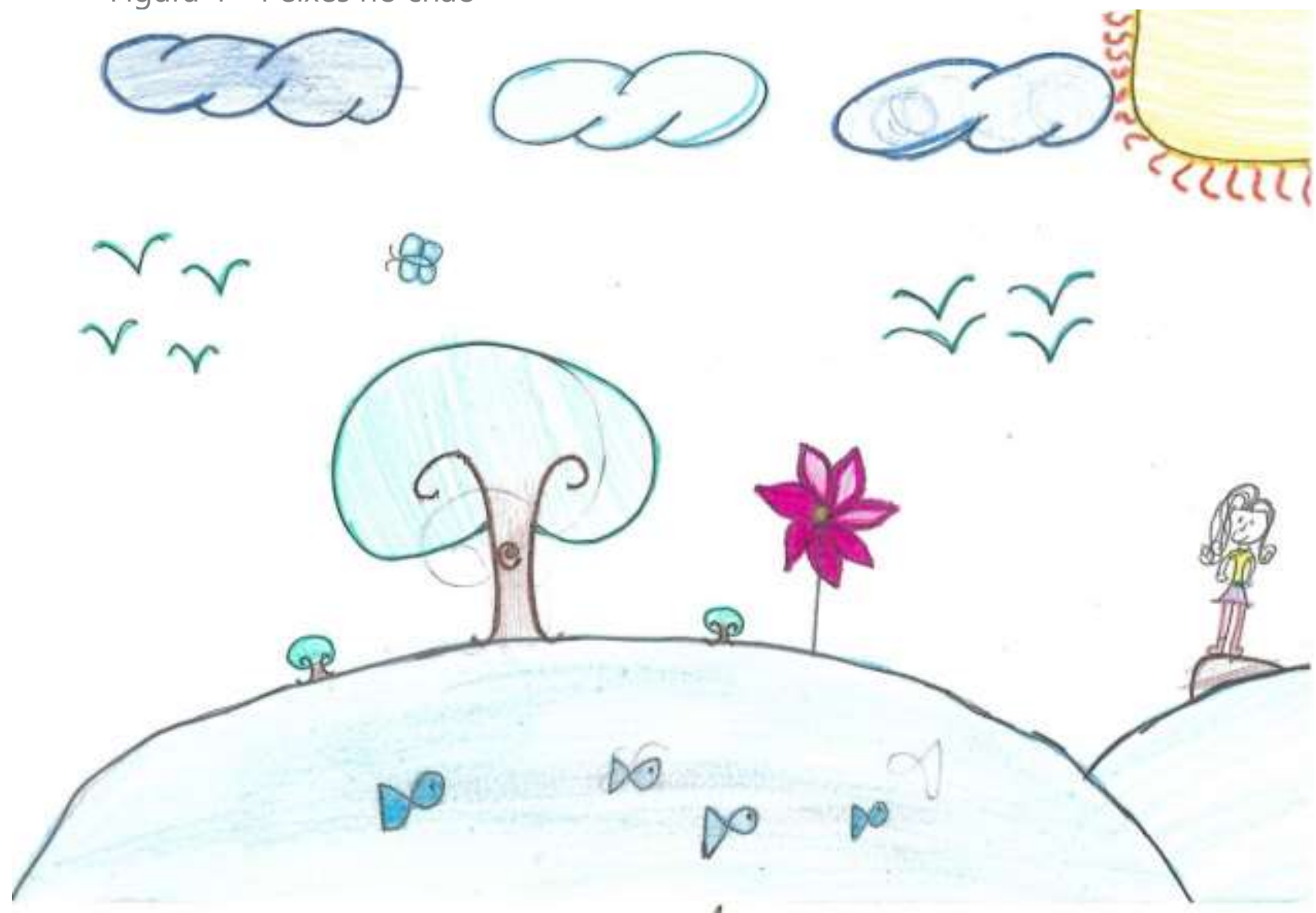

Fonte: Acervo particular dos autores (setembro de 2018).

Legenda: Desenho ilustrado por Emanuelly (9 anos).

A natureza é presentificada por árvores, animais, sol, nuvens, pássaros, flores, rios, frutas e pela inserção de um novo elemento, o ser humano. Ao retratar a paisagem a criança passa a se enxergar como parte dela ao inserir personagens humanos. Ao introduzir o homem na natureza a criança expõe uma relação harmônica, na qual o ser humano não demonstra superioridade, portando-se como parte dela, assim como a chuva, vem para dar vida, sons e cores e complementar essa natureza que ele (criança/homem) agrega a esta composição. Dardel (2011) anuncia a existência de uma geografia mítica em que, na relação do homem com a Terra, era doado um sentido essencialmente qualitativo, a Terra era fonte de vida, origem e presença, onde o homem se sentia acolhido. Essa relação é perturbada no momento histórico em que o homem 
se auto afirmou como indivíduo superior a natureza, e a Terra em sua realidade circundante é destituída de seu papel original, ela perde a sua "alma" ao ser dessacralizada, porém, as experiências vividas levam a um caminho de retorno ao encantamento da Terra, "[...] como continua sendo para crianças pequenas, para quem o Sol, as árvores, as "coisas" estão vivas [...] que vão e vem segundo nos afastemos ou nos aproximemos" (DARDEL, 2011, p. 65).

A natureza existe sem o homem como nas primeiras ilustrações realizadas pelas crianças, mas o homem não pode existir sem a natureza. Parte das crianças, sujeitos dessa pesquisa, não fizeram distinção ao se inserir na natureza presentificada pelos seus diversos elementos, como uma flor, um animal ou uma árvore. Desejamos que esses desenhos sejam vistos como formas de "escritas da Terra", de tal maneira que essas escritas possam comportar novas leituras no âmbito da formação para a docência na Educação Infantil e nas Séries Iniciais do Ensino Fundamental, fase da vida em que o ser humano está voltado para a curiosidade e pode reescrever as suas histórias e geografias a partir de suas experiências cotidianas, psíquicas e sociais como um devir para que o mundo circundante seja mais sustentável.

\subsection{Narrando as brincadeiras}

A segunda metodologia foi uma roda de conversa, em que as crianças puderam falar do que gostavam de brincar, cada uma pôde falar um pouco das suas brincadeiras preferidas, momento em que passaram por uma "experiência de sua presença carnal na palavra", como diria Merleau-Ponty (1989, p. 83).

A professora pergunta:

- Quais são as suas brincadeiras preferidas?

As crianças respondem:

"Eu gosto de brincar de robô, de bola, dinossauro, luta, piscina, pipa bicicleta, jogo da memória, slaime, desafio da garrafa e também gosto de brincar com meu cachorro". (Pietro) 
"Eu gosto de brincar com meu cachorro, de barbie, pular corda, escondeesconde, eu gosto de brincar na piscina e também fazer slaime, eu gosto de jogar no x-box, andar de bicicleta e pular na cama elástica". (Madeleine)

"Eu gosto de brincar de esconde-esconde, pega-pega, pular corda, bola, casinha, escolinha, mamãe e filhinha, comidinha, bicicleta, dança da cadeira e bola queimada". (Isabelly)

"Eu gosto de andar de bicicleta na minha casa, de skate, gosto de brincar com meu cachorro, gosto de brincar no escorregador, pega-pega e carrinho". (Calebe)

"Eu gosto de brincar de pega-pega, jogar bola, queimada, esconde-esconde, nadar na piscina, castelinho de areia, carrinho de rolimã, coelho sai da toca e dança da cadeira". (Nathan)

"Eu gosto de brincar de esconde-esconde, cobra cega, pega-pega, brincar na piscina, ir na loja de brinquedos, brincar de morceguinho-morcegão, boneca, comidinha, dança da cadeira e slime". (Yasmin)

"Cobra cega, boneca barbie, esconde-esconde, pega-pega, brincar na piscina, médico, escolinha, veterinária e brincar com a minha cachorra". (Kamily)

"Cobra cega, pega-pega, pular corda, dominó, dança das cadeiras, quebra cabeça, zerinho, duro ou mole". (Ana Beatriz)

"Bola queimada, esconde-esconde, alerta, dança das cadeiras, luta, cobra cega, batata quente, bicicleta, verdade ou desafio". (Pedro)

"Roller, bambolê, bicicleta, pular corda, basquete, escolinha, jogo de celular, pega-pega, queimada, esconde-esconde" (Diego)

"Eu gosto de brincar de pega-pega, esconde-esconde, boneca barbie, cobra cega, escolinha, verdade ou desafio, estrelinha, escritório, mamãe e filhinha, e brincar na piscina". (Dafni)

"Eu gosto de brincar de carros, carrinho de controle remoto, escondeesconde, pega-pega, estatua, e minha brincadeira preferida é bola queimada e também piscina". (Gustavo)

"Pega-pega, cobra cega, esconde-esconde, piscina, boneca, xadrez, bola, carrinho, ver as nuvens, dança das cadeiras, bola queimada e slime". (Sara)

Essas narrativas permitem compreender, em algum grau, a realidade cotidiana das crianças, seus ritmos próprios e interesses, revelando a qualidade das relações que mantêm com sua corporeidade por meio do brincar. Tais relatos levam a um sentimento de felicidade e certa nostalgia para as pessoas cujas brincadeiras fizeram parte de sua 
infância. "Quando falo ou quando compreendo, experimento a presença do outrem em mim ou de mim em outrem [...]" (MERLEAU-PONTY, 1989, p. 83).

Por meio das narrativas, as crianças mostram uma realidade com brincadeiras favoráveis ao desenvolvimento da corporeidade, pois ao relatar as brincadeiras preferidas, apenas uma criança citou o X-box (vídeo game), em meio a outras brincadeiras simples como pega-pega, bola queimada, esconde-esconde, entre outras. Como as crianças são moradoras em bairros carentes afastados do centro da cidade, a hipótese inicial dessa pesquisa foi que, por esta razão, as mesmas possuíam mais liberdade para juntar os amigos para brincar na rua, porém tal hipótese não se confirmou totalmente. As investigações mostraram que, a maior parte das brincadeiras citadas pelas crianças são realizadas na escola, como a dança das cadeiras, bola queimada, pega-pega, pular corda, cobra cega, isso demonstra a importância do espaço escolar para oferecer à criança atividades lúdicas, incentivando a sua corporeidade e imaginação, visto que a liberdade favorece a imaginação criadora. Na escola a criança está em contato com outras crianças e as possibilidades de brincadeiras se expandem, em suas casas muitas vezes são sozinhas e suas atividades tendem a ser mais individualizadas. Em algumas falas é possível notar que as crianças gostam de brincar com seu animal de estimação, muitas relataram que gostam de brincar na piscina, um local favorável ao desenvolvimento da corporeidade em diversos âmbitos, pois ao estar imerso na água a densidade corporal é diferente e muitas brincadeiras podem surgir.

Ao narrarem as suas brincadeiras preferidas as crianças expressam/revelam a extensão de sua realidade, onde relatam brincadeiras que reproduzem aspectos do mundo da vida, como escolinha, mamãe e filhinha, veterinário, casinha, escritório, entre outras, do qual fazem parte. Por meio das brincadeiras podemos conhecer a realidade da criança e como ela se posiciona no mundo e o contato com a natureza fora delas, expressando-se de diversas formas, tanto na fala, nos gestos e olhares, o que demonstra o seu posicionamento no mundo. 


\subsection{Aula-Passeio no Jardim Botânico}

Apesar de viverem em bairros periféricos e gozarem de um pouco mais de liberdade, as crianças vivem emparedadas, tanto na escola, quanto em casa. Esta circunstância de emparedamento vem se tornando parte da vida da maioria, na escola ficam sentadas em suas carteiras, aprendendo o mundo de forma abstrata. Uma proposta interessante para a formação de professores atuantes na escola básica, foi apresentada no livro organizado por Tiriba (2018), em que se buscou o desemparedamento da infância, o qual consiste basicamente em deixar a criança usufruir do mundo/natureza livre das paredes. Embasando-se nessa proposta de desemparedamento, propomos aos estudantes um passeio no Jardim Botânico de Londrina, como parte dessa pesquisa, onde pudessem desfrutar de momentos junto à natureza, explorando-a de diversas formas, transformando-se e desenvolvendo a sua corporeidade.

Com mais de 1 milhão de metros quadrados de mata nativa, nascentes e rios, o Jardim Botânico de Londrina é uma das mais importantes unidades de pesquisa e conservação de espécies nativas e exóticas no Paraná, é um espaço voltado à proteção e cultivo de espécies silvestres raras, ameaçadas de extinção, ou econômica e ecologicamente importantes para a restauração e reabilitação da fauna e flora paranaenseii (Figura 5). 
Figura 5 - Mapa indicando a localização do Jardim Botânico de Londrina, PR e vista do Espelho d'água localizado dentro do JB.

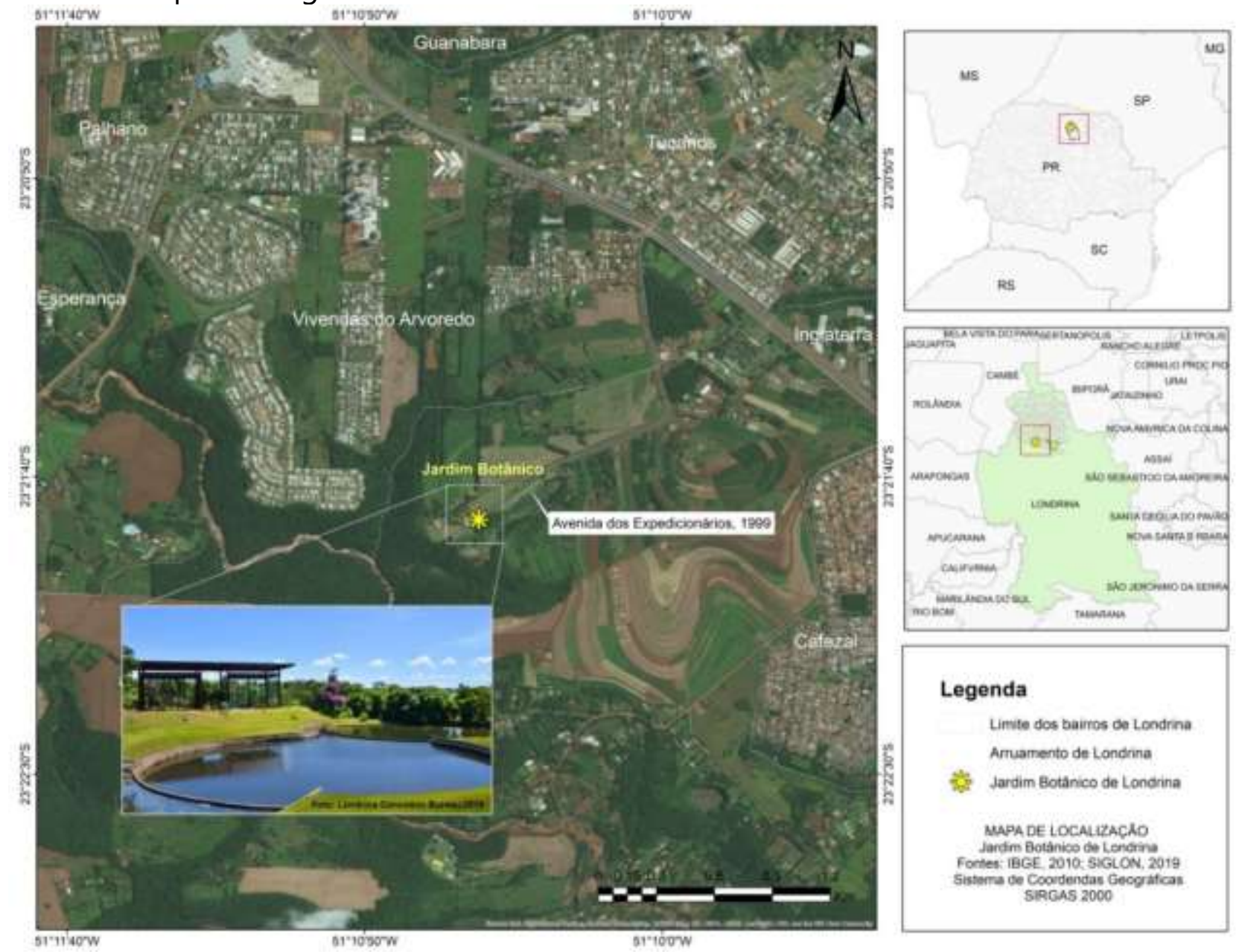

Fonte: IBGE, 2010; SIGLON, 2019. Sistema de Coordenadas Geográficas - SIRGAS, 2000.

Nesse espaço de interação com a fauna e flora, as crianças se sentiram livres para brincar de forma pueril, desfrutando do momento e de variadas formas. No início do passeio a monitora realizou algumas explicações para as crianças a respeito dos cuidados e das características do trajeto que iriam percorrer, através de explanações mostrou a importância de algumas árvores em conjunto com o seu habitat. Eis que a imaginação infantil floresceu e a curiosidade tomou conta, as dúvidas emergiram e surgiram as perguntas. A busca por compreender o desconhecido predominou e muitos questionamentos foram feitos de forma entusiasmada. Durante o percurso outros questionamentos surgiram, sobre a disposição da vegetação, o sobrevoar das aves, eis que ao perceber um movimento rápido nas folhas das árvores, as alunas, se reuniram para procurar o que causou esse alvoroço e se depararam com um pássaro na copa das 
árvores, embelezando as suas folhas (Figura 6). O fascínio tomou conta e permitiu que alguns minutos do passeio fossem dedicados para a contemplação deste espetáculo da natureza.

Figura 6: Olhe para cima

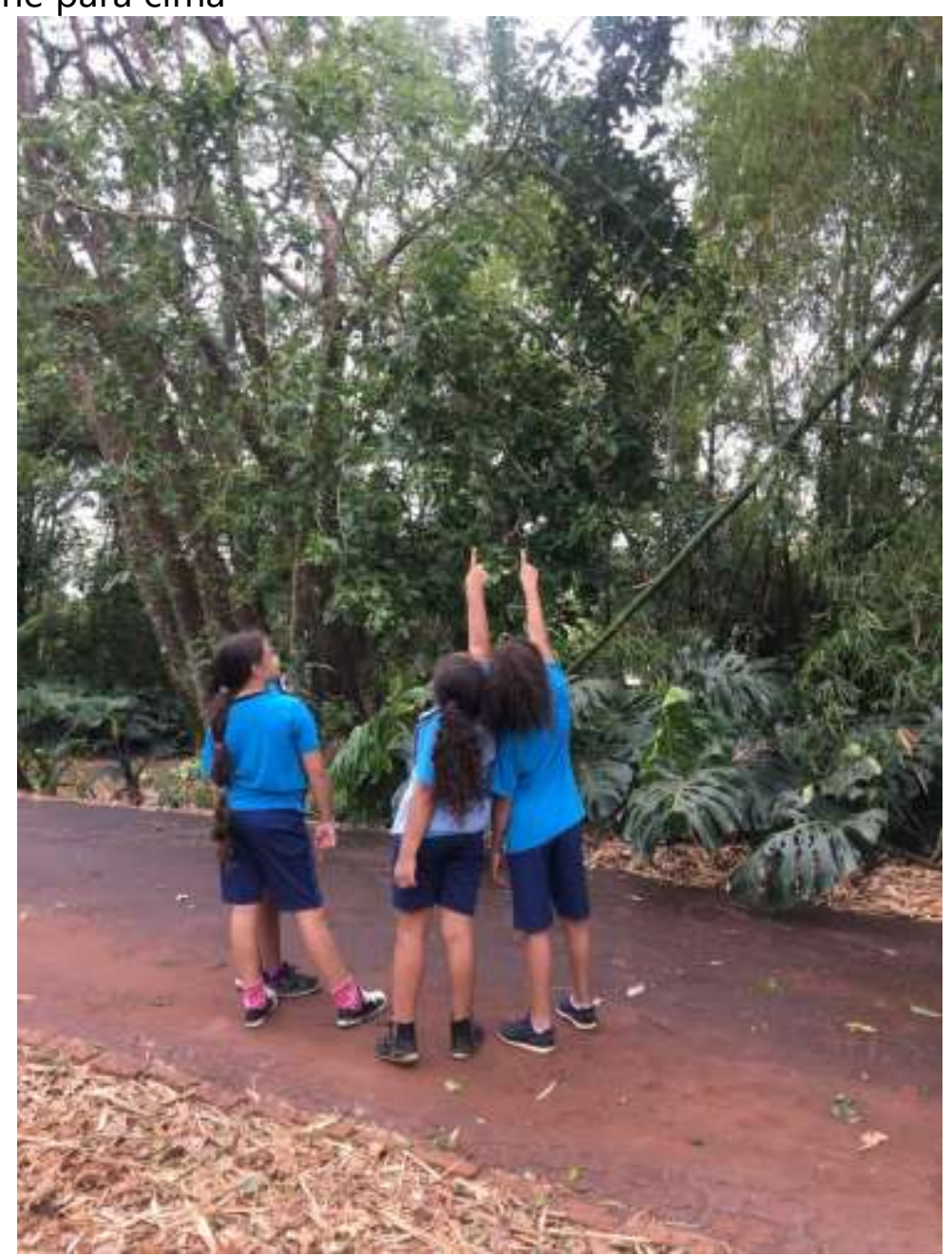

Fonte: Acervo particular dos autores (setembro de 2018).

Legenda: imagem captada durante a aula-passeio no Jardim Botânico, Londrina,PR.

Ao caminhar pelos espaços do Jardim Botânico, a turma se deparou com alguns troncos de árvores cortados, dispersos pelo chão, a intuição de pequenos geógrafos logo floresceu e os mesmos começaram a escalar e a aproveitar os pequenos bancos formados pelos troncos das árvores. As imagens fotográficas eternizam a interação das crianças com a natureza modificada em decorrência da intervenção humana. Durante o passeio, algo que chamou a atenção das crianças foi o espelho d'agua projetado no interior do Jardim Botânico, embelezando ainda mais aquele espaço. O grande lago 
permitiu as crianças aproveitarem seus arredores e ver sua imagem refletida na água, assim como alguns pássaros que por ali passavam e aproveitavam para se refrescar.

O livre brincar na natureza foi o ponto alto do nosso passeio, momentos de alegria e diversão foram vivenciados pelas crianças que aproveitaram os elementos da natureza, como as árvores, o gramado e o lago, inventando as mais variadas brincadeiras. A imaginação fluiu livre, permitindo-os sentir integrados a natureza por alguns instantes.

Reconhecemos o brincar livre como intrínseco à infância, como linguagem essencial por meio da qual a criança descobre e apreende o mundo. $\mathrm{Na}$ natureza, a criança brinca através da inteligência de seu corpo e está potente. Ao mesmo tempo, a natureza é ninho e refúgio para momentos de solitude e introspecção (TIRIBA, 2018, p.12).

No momento em que foi realizada a trilha, uma mensagem chamou a atenção de algumas crianças, as quais, no auge do processo de alfabetização, se dispuseram a lêla: "Da Natureza nada se tira além de fotos, nada se deixa além de pegadas e nada se leva além de lembranças". Durante o passeio pela trilha, acompanhados por monitores, as crianças puderam sentir a natureza de perto, conheceram espécies de árvores e al guns animais que habitam esta região, vivenciando momentos de interação e aprendizado. Após finalizar o passeio pelas trilhas na mata e ao redor do lago, foi separado um tempo para reflexão, em que todos puderam falar sobre as suas percepções e sentimentos a partir daquela experiência diferenciada, se comparada às atividades escolares cotidianas. Ao final das atividades, um dos momentos mais esperados pelas crianças - a hora do piquenique ao ar livre - ocorreu diante da beleza e leveza daquela paisagem e do desfrutar de comidas saborosas, repondo as energias depois de tanta agitação.

Ao vivenciar junto das crianças essa experiência de aula-passeio, tanto a ansiedade pré-passeio, a euforia durante o passeio e os relatos pós-passeio, trouxeram a força da sintonia da criança com a natureza, como se de fato elas estivessem em seu habitat natural. Quando se propôs o passeio as crianças gostaram da ideia, algumas já conheciam o lugar e para outras tudo seria novidade. A possibilidade do contato mexeu em seus imaginários e a experiência pós-contato criou memórias e despertou sentimentos que não serão facilmente esquecidos. Em cada momento de interação com 
as crianças, observamos a curiosidade e a vontade de experienciar aquele lugar e percebê-lo em sua imensidão. Acompanhados de monitores as crianças queriam conhecer tudo e nada poderia as impedir de perguntar tudo que viesse à cabeça. $\mathrm{A}$ apreciação e o fascínio pela natureza no Jardim Botânico saltava aos olhos das crianças, transmitindo sentimentos de pureza e ingenuidade, típicos da infância. As crianças manifestaram a vontade de usufruir do seu corpo e colocá-lo em contato com o mundo circundante, elas queriam provar, tocar, cheirar, olhar, correr, pular e se integrar à natureza fora delas.

O tempo foi curto, mas significativo diante da natureza com suas cores, texturas, cheiros e a presença das crianças para dividirem as suas percepções, curiosidades e experiências. Após a aula-passeio, a atividade foi finalizada com uma roda de conversa, seguindo a ideia de que "o real deve ser descrito, não construído ou constituído" (MERLEAU-PONTY, 2011, p.5), ressaltando a importância de se considerar a natureza pelos olhos da infância, pois as falas das crianças, descritas a partir de suas experiências e percepções, suplantam qualquer tentativa de análise, descrição ou interpretação pelo olhar de um adulto. Pelas narrativas foi possível compreender um pouco das percepções que as crianças tiveram sobre a experiência de sair da sala de aula e aprender em ambientes abertos e livres.

Aula-passeio no Jardim Botânico

A professora pergunta:

- O que vocês perceberam e sentiram, ao sair da sala e ir para o Jardim Botânico?

As crianças respondem

"O passeio no Jardim Botânico foi bem legal, a parte que eu mais gostei foi quando nós passeamos na trilha e na roleta para entrar". (Pedro)

"Eu achei o Jardim Botânico muito bonito, tinha árvores e pato, eu aprendi que tem que cuidar das plantas, se não elas morrem e os professores disseram que o rio era um espelho d'agua, eu escorreguei na grama, eu e minha amiga pisamos no tronco e viu que o tronco estava com sangue". (Emily) 
"Eu gostei de ir ao cinema, e eu vi uma árvore que produz água e depois eu vi uma planta que se chamava suculenta e cactos, eu gostei também de fazer a roda e o piquenique, brinquei um monte e eu senti a natureza, eu gostei muitos das árvores". (Nathan)

"Eu senti um cheiro de alho e vi um pato, e teve um quero-quero, tinha uma ponte e rio e mais uma árvore grande, eu vi uma floresta e troncos grandes, e a gente subiu nos troncos, e nós assistimos um vídeo do Jardim Botânico, e nós fizemos grupos e brincamos de pega-pega e também um piquenique bem gostoso". (Pietro)

"Nós chegamos lá e daí começou a chover, nós fomos ver um filminho sobre o Jardim Botânico, nós vimos vários tipos de árvores no filminho, depois fomos beber bastante água, nós brincamos um pouco e voltamos para dentro da salinha, vimos vários cartazes e vimos na salinha um galho em formato de jacaré, e fomos dar uma caminhada pelo Jardim Botânico, e nós vimos as árvores invasoras, vimos patos, escorregamos na grama, vimos quero-quero, tiramos fotos, a árvore de pau d'alho e terminou a nossa caminhada, passou uns minutos e fomos fazer a trilha eu vi vários tipos de flores e vários galhos caídos, muitas placas e voltamos e fizemos um piquenique e brincamos mais um pouco e acabou o passeio". (Yasmin)

"Eu vi uma árvore pau d'alho, fui na trilha, assistimos filme, nós brincamos, fizemos piquenique, tiramos fotos, sentimos, tocamos e experimentamos a natureza, sentamos no banco da ponte, vimos o espelho d'agua, vimos pato nadando e corremos, brincamos de pega-pega e foi muito divertido". (Sara)

"Eu fui no Jardim Botânico e eu vi um bambu e o lago, e também ninho de passarinho e pato, árvore, tinha jacaré, mas mataram o jacaré, eu fiz piquenique e comi bastante, vi pedras grandes e pequenas, e tem árvore que é máquina, a árvore produz água, eu assisti dois filmes e foi bem legal ir no Jardim Botânico". (Gabrielly)

"O Jardim Botânico é uma reserva da natureza com árvores, pássaros, fontes de água, animais, formigas, peixes, quero-quero, patos, nunca quero me esquecer de lá". (Matheus)

"Eu fui no passeio no Jardim Botânico e eu senti o ar, foi muito legal, nós andamos um monte e eu vi um passarinho" (Isabelly)

"Primeiro nós assistimos a história do Jardim Botânico, na história aparecia a máquina de água que era uma árvore muito grande e a raiz era do tamanho de uma pessoa, e a história também falava do desmatamento, depois que vimos a história nós passamos no meio do mato, quando nós passamos no mato nós vimos dois patos lá no lago e três quero-quero e chegamos em uma árvore que tinha cheiro de alho, e depois passamos no "triuzinho" e depois fizemos um piquenique, brincamos um poucos e fomos embora" (Ana Beatriz)

"Que eu fazia parte da natureza, e eu senti o gosto e o cheiro de uma árvore que cheirava alho, tinha uma lagoa que se chamava lago do espelho, porque dava pra 
ver você no lago, e tinha árvores invasoras, elas matavam todas as árvores". (Madeleine)

"No Jardim Botânico tinha um monte de rio chamado espelho d'agua, e também tinha árvore chamada pau d'alho, também tinha jacaré lá, só que mataram ele na pedrada, coitado do jacaré, tinha um pato que não parava de fazer quá quá quá, lá no jardim botânico tinha uma grama escorregadiça, e paramos para escorregar, também tiramos muitas fotos". (Diego)

"Eu fui no Jardim Botânico e lá nós assistimos a história do Jardim Botânico e nós vimos a máquina de água, nós vimos as árvores invasoras, cactos, nós fizemos uma trilha curta, vimos pau d'alho, fizemos piquenique, comemos, bebemos, brincamos e nós divertimos muito". (Kamily)

Pelas narrativas fica clara a simplicidade da criança ao descrever os momentos mais significativos durante o passeio, bem como a forma como elas expressaram sua experiência através do vocabulário infantil, algumas palavras aparecem no diminutivo, como "triuzinho", "salinha", "filminho", também a presença do jacaré na fala de algumas crianças, que se surpreenderam com o seu fim trágico, e sentiram pena do pobre jacaré, que, de acordo com o que foi narrado a eles durante o passeio, foi morto a pedradas por algumas pessoas que visitavam o Jardim Botânico. A admiração pelo espelho d'água ficou evidente em alguns relatos, visto que em algumas narrativas, as crianças citam o "lago do espelho". É impressionante a sensibilidade delas ao rememorarem cenas do filme assistido no início do passeio, ao reconhecerem o ciclo da água, a absorção de água pelas plantas, comparadas a uma máquina d'água, além de pontuarem a história do Jardim Botânico. As crianças se interessaram pela árvore pau d'alho, pois durante a trilha o cheiro de alho ficou bem forte e as mesmas questionaram sobre esse cheiro inusitado, sendo esclarecidas as dúvidas pelos monitores que nos acompanhavam.

A diversidade de espécies animais e vegetais foi destacada em vários relatos, quando os mesmos citam a observação de pássaros, peixes, animais de pequeno porte, árvores em diferentes tamanhos, além de seus fragmentos, com galhos e folhas encontrados durante a caminhada e que, por meio da imaginação, se tornavam brinquedos para alguns. O brincar e o escalar os troncos das árvores, promoveram um contado breve, porém integral da criança com os elementos da natureza, ainda não experienciado por grande parte delas. Durante as observações o som dos pássaros 
pôde ser ouvido e seus hábitos puderam ser percebidos sutilmente. A interação das aves de diferentes espécies, com outros animais e elementos da paisagem proporcionaram aos sujeitos uma visão de ecossistema singular, na qual os mesmos puderam observar diferentes populações de espécies interagindo com os componentes não vivos do meio. O contato com a natureza natural por meio de sensações como o cheiro, o tocar na água, o caminhar por um "triuzinho" com solo acidentado, o escorregar na grama, proporcionou emoções novas, as quais tendem a perpetuarem nas memórias infantis, além de fundamentar a construção de indivíduos que respeitam a natureza como ser e, não, como recurso a ser explorado.

Por meio da aula-passeio no Jardim Botânico, foi possível observar o comportamento infantil em espaços abertos, com a presença marcante do mundo natural. Pela possibilidade de liberdade, de forma espontânea, as crianças demonstraram como se dá o contato delas com a natureza, o que leva a acreditar que elas não dispõem desse tipo de contato em seu dia-a-dia, assim como a maioria das crianças que vivem a vida urbana, com poucos ou quase nenhum momento de contato e convívio em áreas verdes.

Londrina ainda disponibiliza outros espaços reservados à conservação da natureza além do Jardim Botânico, como o Parque Arthur Thomas, a Mata dos Godoy e o Lago Igapó, que mesmo sendo localizado na área central de Londrina, dispõe de gramados, árvores e animais de porte pequeno em seus arredores, entre outros. No entanto, fica a cargo das escolas e das famílias estimularem este tipo de convívio e empatia pela natureza. Essas experiências do corpo com a natureza ainda na infância são primordiais para o desenvolvimento humano, social e a consciência ambiental, mesmo que, nessa fase, ainda não se compreenda a magnitude e importância de sua preservação. As experimentações desta pesquisa mostraram que é preciso se reconectar com a natureza desde a mais tenra idade, pois ao serem estimuladas, as crianças pareciam voltar às suas origens sensitivas, intuitivas, corpóreas, como procuramos demonstrar em vários momentos da nossa pesquisa. 


\section{CONSIDERAÇÕES FINAIS}

A presente pesquisa se debruçou na correlação entre criança e natureza na cidade, com base nos estudos de Merleau-Ponty, que aponta a não distinção entre homem e natureza. Diante das questões iniciais deste trabalho: Qual natureza estas crianças vivenciam atualmente? Quais são suas brincadeiras preferidas? A pesquisa propôs um estudo, buscando pensar o modo de vida e as ações contemporâneas das crianças na escala da experiência. O contato com a natureza proporciona a criança o desenvolvimento de diversas habilidades, ampliando suas memórias e sensações, e, principalmente, contribuindo de forma efetiva para desenvolver a sua corporeidade, intelecto e afetividade. O contato com a natureza se mostrou essencial para o desenvolvimento físico e emocional da criança.

Os resultados apontaram que é na infância que frutos importantes podem ser semeados, visto que durante a pesquisa observou-se que as crianças necessitam manter um contato com a natureza fora delas, criando laços com o seu eu-natural e enxergando-se como parte da natureza e não como detentoras dela. A compreensão das experiências da criança, bem como a forma como ela se relaciona com o mundo em si e com a natureza, indicam a necessidade de uma educação ambiental vivencial, mediada pela escola, provendo a criança de experiências que visam seu desenvolvimento humano e altruísta.

Espera-se ampliar o debate sobre o papel da docência na mediação entre a criança e a natureza. Este trabalho se revelou como possibilidade investigativa ao passo que realizou experimentações no espaço-tempo escolar, onde procurou-se dar liberdade a imaginação das crianças participantes e protagonistas de aprendizagens conectadas com a vida. Ao responder os questionamentos feitos no início da pesquisa outras suposições foram levantadas, as quais podem servir de subsídio para o desenvolvimento de estudos futuros. E, se essas crianças fossem de uma realidade mais abastada, como seriam suas brincadeiras e como dar-se-ia o seu contato com a natureza? A hipótese é de que há diferenças ao se comparar as brincadeiras e a relação da criança com a natureza em grupos de distintas classes sociais. No entanto, não fez 
parte do escopo desta pesquisa investigar tal realidade, o que torna possível a realização de um novo estudo de caráter comparativo e exploratório.

\section{AGRADECIMENTOS}

Agradecemos ao bolsistas do Programa de Educação Tutorial (PET) do Curso de Geografia da Universidade Estadual de Londrina/UEL pela monitoria nas trilhas realizadas durante a aula-passeio no Jardim Botânico de Londrina, PR.

\section{REFERÊNCIAS}

DARDEL, E. O homem e a Terra: natureza da realidade geográfica. Trad. Werther Holzer. São Paulo: Perspectiva, 2011.

ECHEVERRI, A. P.N. El Reencantamiento del mundo. Programa de las Naciones Unidas para el Medio Ambiente - PNUMA - Oficina Regional para América Latina y el Caribe: Manizales, 2004.

FREINET, C. As técnicas Freinet da Escola Moderna. Trad. Silva Letra. Lisboa: Editorial Estampa, 1973.

LONDRINA. Secretaria do Meio Ambiente e Recursos Hídricos - Jardim Botânico de Londrina. Disponível em:

http://www.meioambiente.pr.gov.br/modules/conteudo/conteudo.php?conteudo=137 Acesso em: 10 jan. 2019.

LOUV, R. A última criança na natureza. São Paulo: Aquariana, 2016.

LOWENTHAL, D. Geography, Experience, and Imagination: Towards a Geographical epistemology. Annals of the Association of American Geographers, v.51. n.3, 1961.

MERLEAU-PONTY, M. A natureza: curso do Collége de France; texto estabelecido e anotado por Dominique Séglard. Trad. Álvaro Cabral. 2 ed. São Paulo: Martins Fontes, 2006.

MERLEAU-PONTY, M. Fenomenologia da percepção. Trad. Carlos Alberto Ribeiro de Moura. 4ed. São Paulo: Martins Fontes, 2011.

MERLEAU-PONTY, M. Psicologia e pedagogia da criança. São Paulo: Martins Fontes, 2001.

MERLEAU-PONTY, M. Vida e Obra. São Paulo: Nova Cultura Ltda, 1989. (Coleção Os Pensadores).

MOURA, J. D. P, Educação Ambiental na Infância: práticas e reflexões. In: PASCHOAL, Jaqueline Delgado. Trabalho pedagógico na educação infantil. Londrina: Humanidades, 2007. 
OLIVIER, G. G. de F. Um olhar sobre o esquema corporal, a imagem corporal, a consciência corporal e a corporeidade. 1995. Dissertação (Mestrado em Educação Física). Universidade Estadual de Campinas, Faculdade de I Educação Física. Campinas, SP.

SILVA, J. Ap. P. da. Corporeidade e natureza: experiência e percepção na infância. 2019. Dissertação (Mestrado em Geografia) - Universidade Estadual de Londrina/UEL, Londrina, 2019.

TELLES, T. C. B. A infância na fenomenologia de Merleau-Ponty: contribuições para a psicologia e para a educação. Revista do Nufen, Belém, v. 6, n. 2, p. 4-13, 2014.

TIRIBA, L. Desemparedamento da infância: a escola como lugar de encontro com a natureza. 2. ed. Rio de Janeiro: Criança e natureza e Alana, 2018.

TUAN, Y. Topofilia: um estudo da percepção, atitudes e valores do meio ambiente. Trad. Lívia de Oliveira. Londrina: Eduel, 2012.

REZENDE, A. M. Concepção fenomenológica da educação. São Paulo: Cortez, 1990.

\footnotetext{
'Aula-passeio foi um termo cunhado educador francês Cèlestin Freinet (1896-1966) em referência às experiências de aulas ao ar livre, afastando-se de aulas no modelo de conferências expositivas (FREINET, C. As técnicas Freinet da Escola Moderna. Tradução: Silva Letra. Lisboa: Editorial Estampa, 1973).

ii Essas características do Jardim Botânico foram coletadas no site, disponível em:

http://www.meioambiente.pr.gov.br/modules/conteudo/conteudo.php?conteudo=137 Acesso em: 10 jan. 2019.
} 